\title{
Modelling the kinetics of seedless guava(Psidium guajava L.) peroxidase inactivation due to heat and thermosonication treatments.
}

\begin{abstract}
Effect of heat and thermosonication on inactivation kinetics of peroxidase in seedless guava have been studied over a temperature range of $80-95^{\circ} \mathrm{C}$. Application of thermosonication was studied at 25,50 and $75 \%$ of radiation intensity at the same temperature range. Ultrasonic wave's intensity had significant $(\mathrm{P}<0.05)$ effect on peroxidase inactivation rate except the $25 \%$ intensity radiation. In both treatments, the enzyme kinetics showed a first-order kinetics model with monophasic behaviour. The activation energy, the rate constants were estimated which proving that the enzyme became more heat labile. Therefore, thermosonication can affect a process with reduced processing time and increased efficiency.
\end{abstract}

Keyword: Peroxidase inactivation; Seedless guava; Thermal inactivation; Thermosonication. 